\title{
Application of biomimetic design in concept of small terrain electric vehicle, MODULO
}

DOI : 10.36909/jer.ICETET.15005

Gajdáč Igor, Konstantová Viera*, Medvecký Štefan

Department of Design and Mechanical Elements, Faculty of Mechanical Engineering, University of Žilina, Univerzitná 8215/1, Žilina, 01026, Slovakia.

*Email: viera.konstantova@fstroj.uniza.sk; Corresponding Author.

\begin{abstract}
Biomimetic Design is based on basic natural principles. One of the basic natural principle is principle of maximum and minimum. Biological structures or systems can achieve maximum performance and durability with minimal material and energy consumption. More developed system in nature, means the more favorable ratio of this principle. Therefore, this natural principle of maximum and minimum is the basis for trends in biomimetic design. Trends of biomimetic design (functional morphology, optimal arrangement, determination of functionality, multi-functionality, energy use, and so on) are presented for concept of small terrain electric vehicle in this paper. The electric vehicle model has 2 parts: front and rear module with a choice of accumulator size, and with a choice of $4 \times 2$ or $4 \times 4$ drives. The transport of people (including injured people) or transport of cargo to hard-to-reach places is main concept idea of terrain electric vehicle. This work is supported by the Slovak Research and Development Agency under the contract no. APVV-18-0457, Special Light Electric Vehicle from Unconventional Materials to Heavy Conditions and Terrain - LEV.
\end{abstract}

Keywords: biomimetic design, functional shape, terrain electric vehicle, vehicle body frame concept. 


\section{INTRODUCTION}

This paper deals with project of new concept of small terrain electric vehicle - Modulo, to heavy conditions and terrain produced from unconventional materials, with modern technologies. The research and development of modern transport vehicles which used unconventional lightweight materials, alternative drives, modular construction and intelligent assistance systems is essential for the further development of intelligent transport in the future. This trend of new solutions leads to the development of structures made of lightweight material structures in order to reduce the negative impact on the environment. How to safe environment and life on the Earth we can learn from Nature. Modern technologies and material were developed and we have to change strategy of usage. Biomimetic design is right way for the next decades-long technical innovations.

\section{FUNDAMENTALS OF BIOMIMETIC DESIGN}

The term biomimetic is a synthesis of bios (life) and mimesis (to imitate, to mimic). Y. BarCohen presented definition about Biomimetic: "This new science represents the study and imitation of nature's methods, designs, and processes. While some of its basic configurations and designs can be copied, many ideas from nature are best adapted when they serve as inspiration for human-made capabilities (A. von Gleich et al., 2009)

Many authors have proposed several definitions of biomimetics; but the underlying idea may be "Learning from nature" (A. von Gleich et al., 2009 \& Y. Bar-Cohen, 2006 \& Benyus, J. M., 1997) According to Armin von Gleich "Biomimetics is the attempt to learn from nature; it deals with the development of innovations on the basis of investigation of natural, evolutionarily optimized biological structures, functions, processes, and systems" (A. von Gleich et al., 2009). Three primary strands of development (functional morphology, signal and information processing and nanobiomimetics) (A. von Gleich et al., 2009). It is also useful to distinguish between three different levels of learning from nature; learning from the results of evolution (hook-and-loop fasteners, the aircraft wing, etc.), learning from the process of evolution (optimization techniques, evolutionary optimization strategy), and learning from the success 
principles of evolution (closed loop economy, adaptability, etc.). The last one level of learning from success principles of evolution is discussed below according to (A. von Gleich et al., 2009). Learning from success principles of evolution is based on an abstraction of the generalizable principles of evolutionary success. These principles serve as an argument for validity that nature creates more ecologically more suitable and lower risk technological solutions. And they can be put into service as guiding principles or models in engineering (biomimetic) design, when the goal is to develop ecologically more beneficial, intelligent, adaptive, flexible, robust, and intrinsically safer technical solutions (A. von Gleich et al., 2009).

\section{Principles of success}

- Solar energy and raw material opportunism (use of that which is proximate available).

- Modularity, hierarchical structuring, and multi-functionality.

- Resource efficiency (with a view to limiting factors) and recycling.

- Resilience (adaptability, diversity, redundancy).

- Self-organization and self-healing.

- Multi-dimensional optimization.

\section{Nature's principles}

J. M. Benyus also mentioned in (J. M. Benyus, 1997) Nature's basic, principles, fundamentals for biomimetic (biomimicry) are following:

- Nature: runs on sunlight,

- Nature used only energy it needs,

- Nature fits form to function,

- Nature recycle everything,

- Nature rewards cooperation,

- Nature bank of diversity,

- Nature demand local expertise,

- Nature curbs excessed from within

- Nature taps the power of limits. 


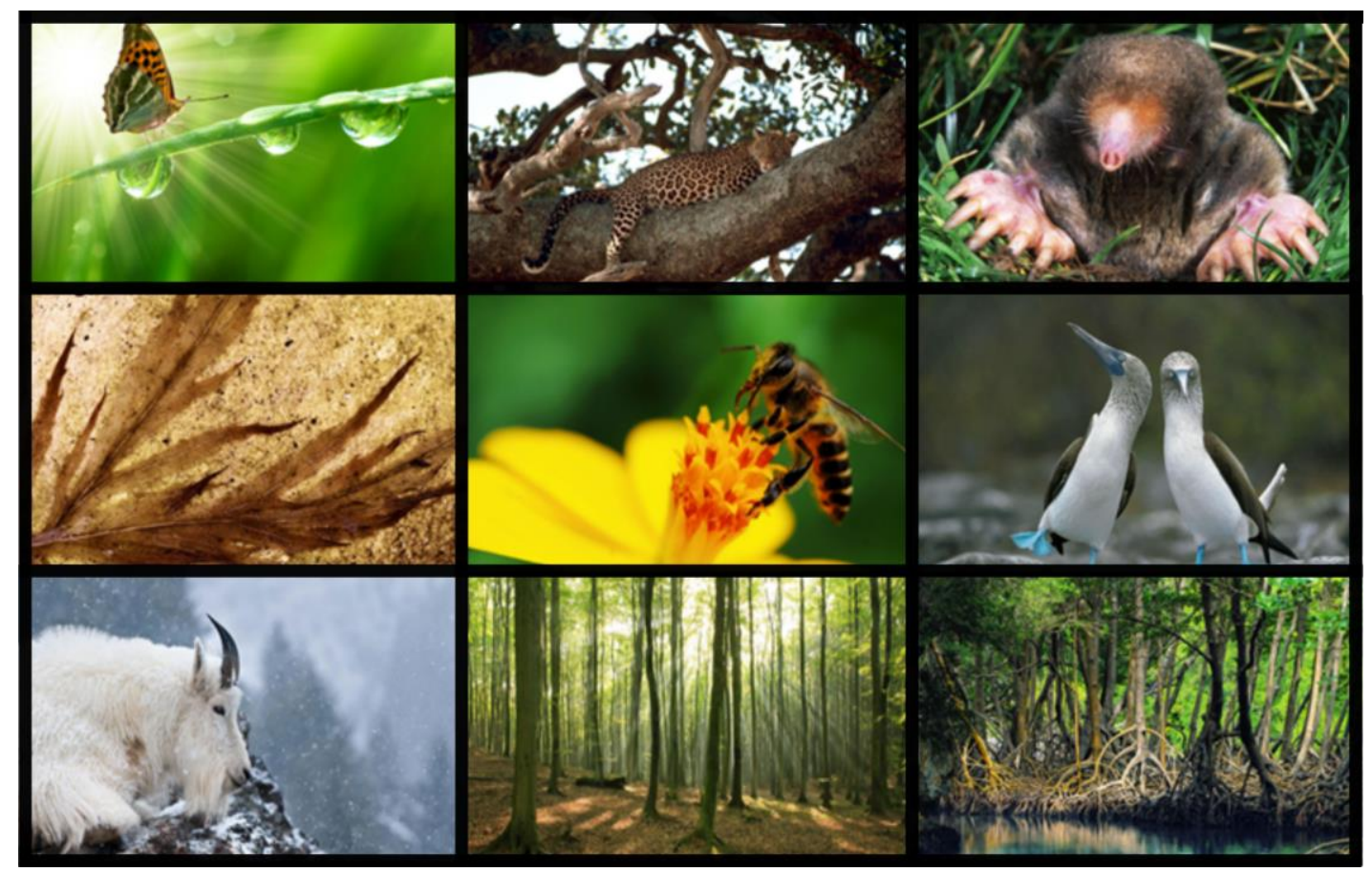

Figure 1 Nature's Laws according to J. M. Benyus.

Nature's Laws (http://www.globalstewards.org/biomimicry-nine-laws-of-nature.htm) are shown in Figure 1. After understanding these Natural's basic principles, the necessary steps on (design spiral) how to implement biomimetic (Almeida, H. A. \& Oliveira, E. S. G., 2016 \& Rossin, K. J., 2010 \& Luca, D. De, 2016 \& Bahill, A. T. \& Botta, R., 2008).

\section{Trends represented by basic natural principles and principle of success}

- Conjunction of the function and structure or form - during designing a system the function must be known first, then the structure or form is proposed.

- Whole optimization - function and structure (shape, composite structure, gradient structure).

- Structure differentiation and functional specialization - integrated several functions in one unit.

- Dynamization - biological structures adapt continuously to the environment during their mutual interaction in nature from the macro to the micro level.

- Multi-functionality - a structure, organ or part of them provides more functions. 
- The use of foreign, resp. surrounding energy - strong competition is a source of various strategies how to obtain or save energy, or use foreign energy.

- Closed process - closed processes ensure sustainable growth in nature.

\section{Innovative principles for biomimetic design}

- Whole optimization.

- Multi-functionality.

- Surroundings compatibility.

- Energy saving.

- Use of renewable energy sources.

- Define lifetime.

- $100 \%$ recycling.

- Connection of network, modularity.

The innovative principles available in the form of living and non-living organisms and structures from the wild. By studying them, we are also able to solve innovative tasks. This study requires knowledge from the field of natural as well as technical sciences. It makes possible to discover a principle in nature, suitable for solving a technical problem. It is not just a matter of copying of the principles developed by nature, but above all of their adaptation to human conditions and to the given field. The sources are not only the observable structures, principles and ways in which creatures work in nature, but also the strategies in which they evolve (A. von Gleich et al., 2009 \& Y. Bar-Cohen, 2006 \& J. M. Benyus, 1997).

From the point of view of successful innovations of technical systems, we must know the successful principles of evolution well, while similar fundamental principles of nature are important, which can be formulated as factors of successful biological development and can also be considered as guidelines for sustainable technologies. The most used trend of biomimetic design is focused on form-function relations interwoven with principle of maximum 
and minimum. Biological structures or systems can achieve maximum performance and durability with minimal material and energy consumption. More developed system in nature, means the more favorable ratio of this principle.

Some of determined principles are comparable with fundamentals of conventional principles of good system design (A. T. Bahill \& R. Botta, 2008).

\section{Biomimetic innovation method}

Creating a technical solution based on the natural models can presented to biomimetic innovation method established by Biomimicry institute, Biomimicry Guild in 2009. The Biomimetic innovative method consists 8 strategic points.

Point 1 - Are sustaineable. Biomimetic follows the principles of life. The principles of life give us instructions how to: build from bottom up, optimize rather than maximize, use free energy, build, cross, accept diversity, adapt and develop, use life-friendly materials and processes, engage in symbiotic relationships, improve the bio-sphere.

Point 2 - Work well. In nature, if the strategy of the created system is not effective, its carrier will die out, disappear from the natural system.

Point 3 - Save energy. Energy in nature is even more expensive than in the human world. Plants must capture and transform it from sunlight and predators must catch it.

Point 4 - Save material cost. Nature is based on an optimal shape, because the shape is cheap but the material is expensive.

Point 5 - Remove waste. Nature ensures the transition of materials and nutrients into the biotope. Point 6 - Reinforce good. Biomimetic help to see obsolete products in a radically different way and this new perspective creates opportunities for innovation.

Point 7 - Create profit. Biomimetic can help create completely new areas in business.

Point 8 - Build a Mark. With biomimetic design can a company become known as an innovative company and at the same time environmentally friendly. 


\section{BASIC TECHNICAL SPECIFICATION OF MODULO VEHICLE}

The MODULO will have two basic parts: front and rear module with a choice of accumulator size, and with a choice of $4 \times 2$ or $4 \times 4$ drives. Maximal speed on the road is about $50 \mathrm{~km} / \mathrm{h}$. Modulo will transport people (including injured people) and cargo to or from hard-to-reach places. More specific requirement needs to be determine for concept of electric modular vehicle, for example max. speed on the road, and in terrain, loading capacity, weight, number of personsize of module, and so on.

\section{Requirements}

Functional requirements: max. speed in terrain, terrain conditions loading capacity, weight, number of person. Design requirements: size of basic module - personal, size of accessory module - cargo, in wheel motors. Operating requirements: sun, rain, dust, on the road, in the water, on the grass, stones, ground, snow, ice; all season, all day/night, simple maintenance, battery modes. Ergonomic requirements: easy operating, easy boarding, comfortable seating. Ecological requirements: silent, operating fluids, reduce emission. Production and economic requirements: come out from project budget, in time. Legislative requirements: according to valid standard.

\section{Description of MODULO design concept}

The basic modularity consists in the design of separate modules, which can be connected to the vehicle with the required properties. Each of the modules will have a separate drive and its control will be subordinate to the main module.

The modularity function should mainly affect characteristics such as useful weight, range, number of people transported and ability to move in hard terrain. Currently, the best choice seems to be the combination of a monocoque with a drive, and extension unit. The monocoque, which would contain a complete drive unit containing full staff, power and control components, will be universal for all modules used. Its body frame would consist of a skeleton and brace. The skeleton itself would be made of lightweight carbon fiber reinforced composite materials. 
Braces would be as main support of body frame and support for the connection of others components.

The internal components would be mainly the control and power supply of the drive. These include batteries and their management, converters and motor control, brake system accessories, components for controlling peripherals in extension unit and hardware for connecting modules.

All these components must be positioned for maximum safety and minimum center of gravity. It is no less important to pay attention to the temperature management of batteries and individual components.

The external components are axles with drive and brake system. The connection with the extension unit is important. The extension unit should consist of a frame structure, which will use the components of the kit from carbon profiles as much as possible, e.g. in the form of 5angles, which represent significant weight savings. Their use is strong enough and their use flexible to meet the requirements of individual modules. It will be necessary to create at least two basic extension unit, a passenger and a cargo unit for the transport of person and material. Such progressive frames are characterized by simplicity and quick assembly.

\section{METHOD PROCESS FOR CREATING A TECHNICAL SOLUTION}

In the case of creating of method process on the base of natural model, an assignment can be defined in the form of a technical problem or in the form of a technical contradiction for body frame concept of electric modular vehicle: low weight of body construction, possibility of configurability, simple assembly of body, body stiffness, possibility to create overlapped areas (transparent and opaque), possibility of easy replacement of a damaged part.

\section{Method process}

- Analysis of the current state of the technical system.

- Revealing a deficiency and design effective improvements based on trends in natural systems. 
- Creating a technical assignment using active verbs used in (https://asknature.org/resource/biomimicry-taxonomy/), biomimicry taxonomy of function.

- Search based on keywords, development trends, or field.

- Selection of relevant natural principles.

- Translation of selected principles into variant technical solutions.

- Selection of the most suitable variant Development of a technical solution.

Four stages of method process are presented in Figure 2.

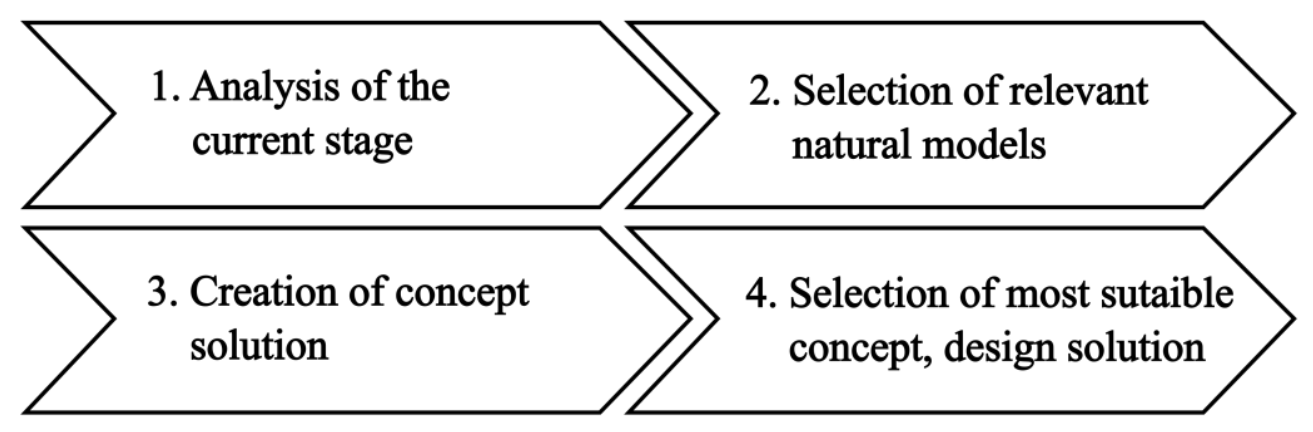

Figure 2 Simplificated process of technical solution creating

\section{ANALYSIS OF CURRENT MARKET}

Many of $4 \times 2$ or $4 \times 4$ drives small vehicles have important disadvantages according to project idea. These conventional vehicles are heavy, huge, noisy and they are not modular. Their concept misses multi-functionality and configurability.

\section{NATURE MODELS AS INSPIRATION}

The Euclid's elements, polygons we can easily recognize in all dimensions in Nature. For example, a hexagonal structure of honey combs was studied in many mechanical models and technical application of it is well known (Y. Bar-Cohen, 2006 \& R. Mishra et al., 2019 \& https://asknature.org/idea/dupont-nomex-and-kevlar-honeycomb-composite-materials/)

According this successful hexagonal structure, a pentagon shape was studied. As Natural model of pentagon can be presented a non-blossom bud of Platycodon grandifloras, called also Balloon 
flower (see Figure 3. right); and out of bloom flower Hibiscus syriacus called also Rose of Sharon (see Figure. 3. left).

A regular pentagon has Schläfli symbol $\{5\}$ and interior angles are $108^{\circ}$. A regular pentagon has five lines of reflectional symmetry, and rotational symmetry of order 5 (through $72^{\circ}, 144^{\circ}$, $216^{\circ}$ and $288^{\circ}$ ). The diagonals of a convex regular pentagon are in the golden ratio to its sides (D. C., Barton \& J. D. Fieldhouse, 2018). With connection of twelve pentagons a dodecahedronwill be created (see Figure 4.). Dodecahedron, also known as regular convex polyhedron - Platonic solid (J. L. Heilbron, 2013 \& E. J. Larson, 2006 \& S. Pischinger \& U. Seiffert, 2016), is one of the five polyhedrons (next: tetrahedron, cube, octahedron, and icosahedron). It's identical faces meet at the same three-dimensional angles (J. L. Heilbron, 2013).
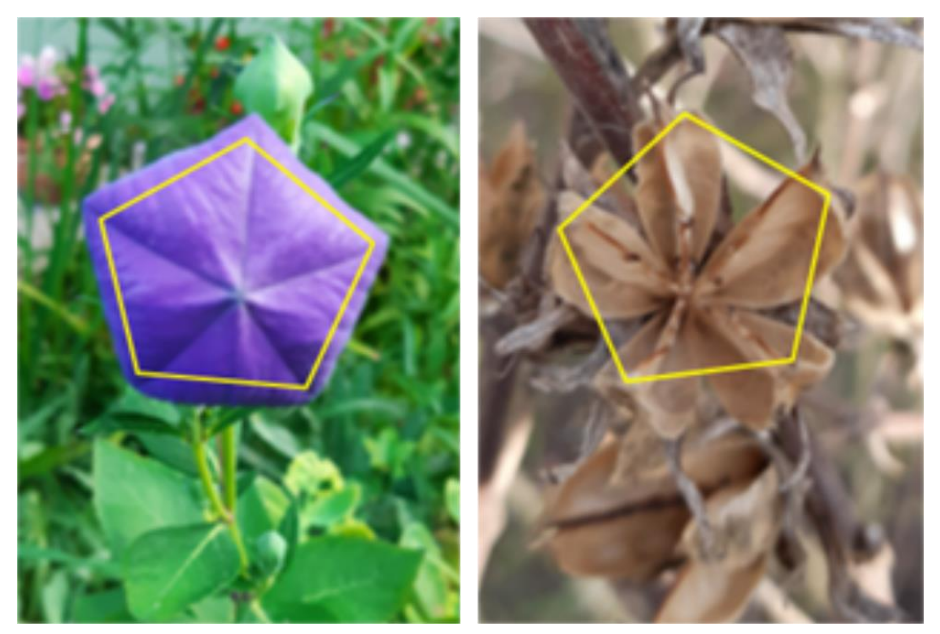

Figure 3 Pentagon shape in Nature models. (photo credit: authors).
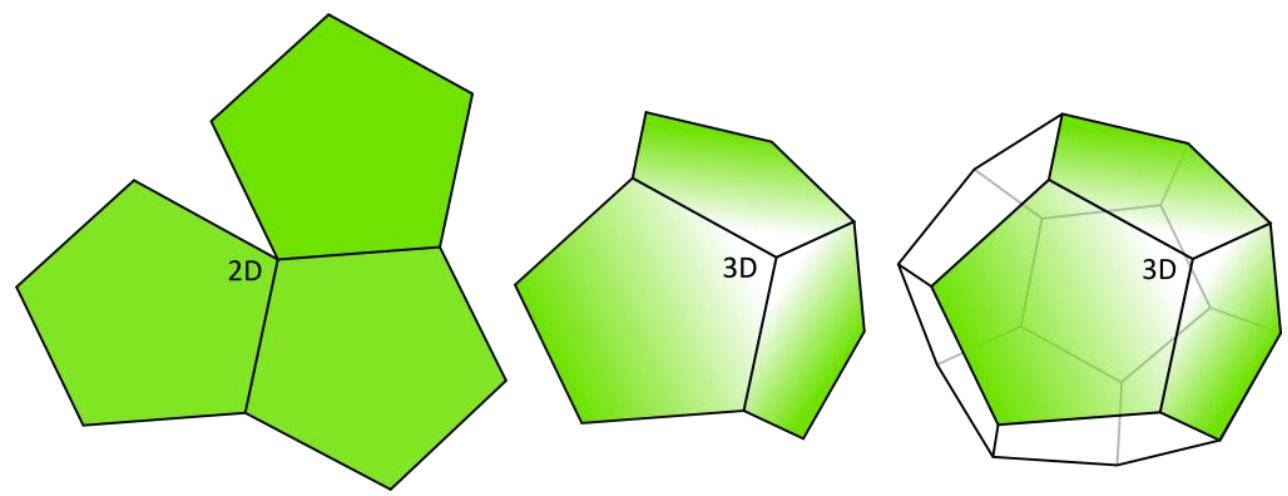

Figure 4 Pentagon shape in Nature models.. 
With 12 pentagons you can fold it to the Dodecahedron. No other configurations are possible with this polygon, just like the square which forms a cube (hexahedron).

Hexagon, cannot fold a solid. As a flat pattern all the "non folding" lines are already touching each other. You can't pop them out of 2D into 3D. Even if you did, the surfaces would intersect (S. Fiolet, 2020)

\section{BIOMIMETIC DESIGN OF BODY FRAME}

The body in general describes the vehicle structures, which can be either self-supporting or nonself-supporting. The most important functions of the supporting body components are ensuring a stable interior, protection of passengers and cargo, absorption of forces and moments, ensuring bending and torsional stiffness, guarantee of energy absorption, providing of attachment points for mounting parts, according to (S. Pischinger \& U. Seiffert, 2016 \& J. Altach et al., 2019).
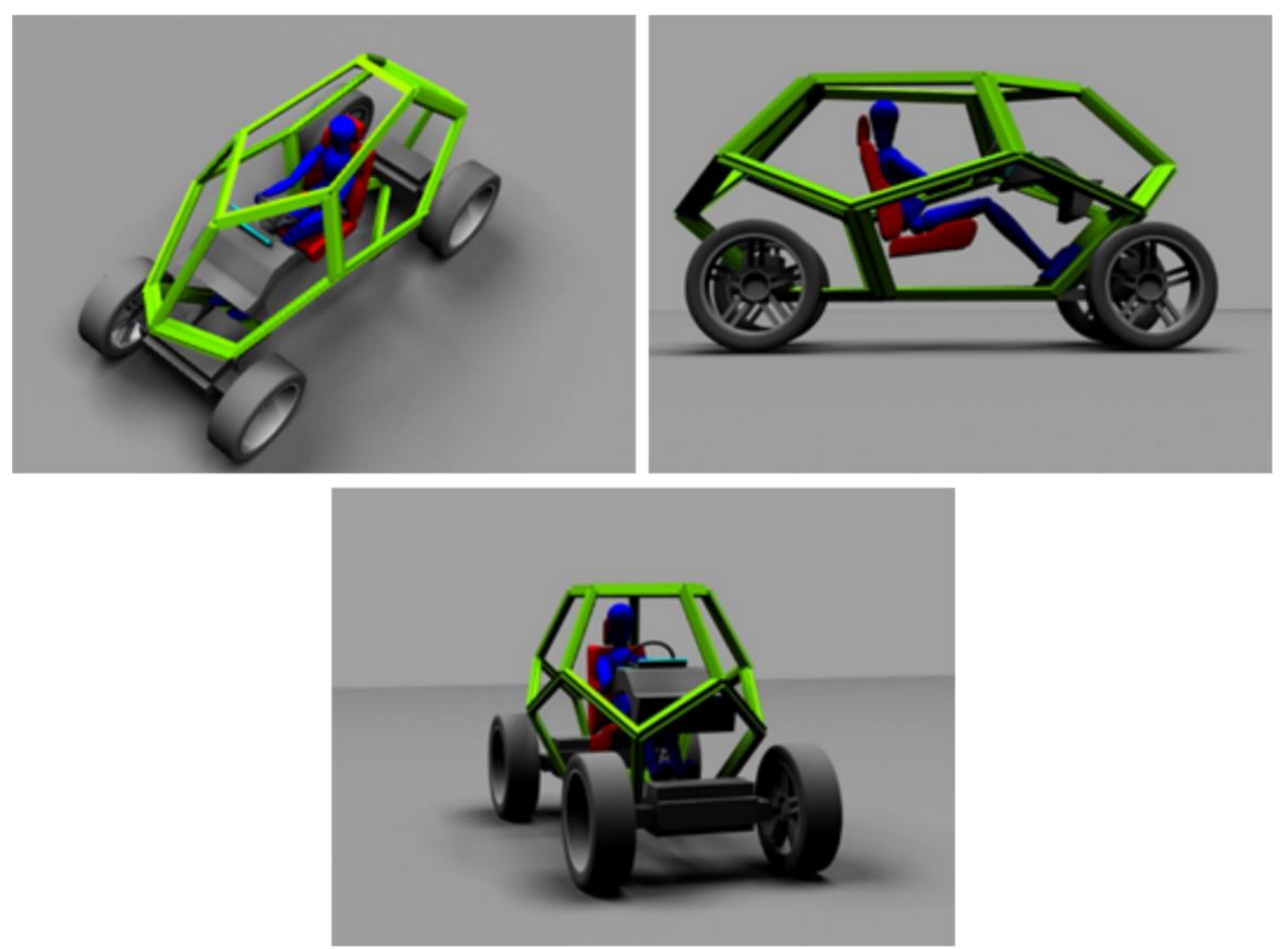

Figure 5 Body frame concept for electric vehicle, top view, side view and front view.

Modular concept of body frame connected from 12 pentagons as irregular dodecahedron is 
shown in Figure 5. This concept is basic configuration and can be rearranged according to the purpose.

\section{SELECTION OF TRENDS AND PRICIPLES OF BIOMIMICRY DESIGN}

A. Description for MODULO vehicle:

- Trends and principles: Connection of function with structure.

- Technical solution: Functional requirements: reconfigurability, possible change of purpose for the transport of persons or persons and cargo. Resulting structure: modular architecture.

- Trends and principles: Optimal arrangement.

- Technical solution: Use of composite structures in all modules mean minimization of space, material, weight and energy consumption, crew protection.

- Trends and principles: Structure differentiation and functional specialization.

- Technical solution: The basic chassis module integrates the protective function of the components, the supporting function for the batteries, the electric drive, the wheel suspension, the fastening of the connecting elements between the chassis modules and carries the module for the crew.

- Trends and principles: Dynamization.

- Technical solution: adaptation to the environment by changing the ground clearance of the vehicle and the stiffness of the suspension

- Trends and principles: Multi-functionality.

- Technical solution: Multi-functionality represents the transport of people and cargo on the road and different terrain, independent operation, adaptation to disabled operators, the possibility of creating various drive arrangements.

- Trends and principles: Compatibility with the environment (adaptability, resistance). Technical solution: Color, high ground clearance, front and body surface shape for 
better clearance in difficult terrain, winch, snow belts.

- Trends and principles: Energy saving.

- Technical solution: Electric drive with energy recovery, modern material. Use of the onboard intelligent energy assistant system.

- Trends and principles: Use of renewable energy sources.

- Technical solution: The vehicle is equipped with portable folding photovoltaic panels.

- Trends and principles: Recyclability.

- Technical solution: Components for the construction of the vehicle will also be designed from recyclable material.

B. Description for modular body frame:

- Trends and principles: Connection of function with structure, functional specialization and multi-functionality of individual segment of 3D body frame

- Technical solution: Functionality, multi-functionality requirements: reconfigurable parts easily removable or replaceable according to the purpose; easily to repair, pentagon elements can be simply glazed, filled with transparent and opaque materials or filled with safety net.

- Trends and principles: whole optimization and energy saving

- Technical solution: A carbon FLP composite material was proposed for production of pentagons segments. The use of a composite material makes it possible to change the dimensions, the angle of connection of the parts, the shape and thus to define the mechanical properties for each pentagonal segment separately this possibility of optimization will save material, weight and energy consumption.

\section{CONCLUSION}

Successful investigation of functional morphology focused on the relationship between biological forms, structures and their functions revealed to the design possibilities of the 
pentagon. This work is not only a copying of a geometric shape into the design of a vehicle frame, but the transformation of a biomimetic form into the development of a new technical system. The modular body frame of the Modulo vehicle is structured from pentagonal segments, it meets a number of relevant trends in the development of natural systems and biomimetic innovative principles, and with a certain degree of simplification it is SMART. Natural systems have the ability to self-heal. Self-healing or re-functioning of the frame part can be performed by a quick and simple replacement of a specific damaged segment.

\section{AKNOWLEDGEMENT}

This work was supported by the Slovak Research and Development Agency under the Contract no. APVV-18-0457.

\section{REFERENCES}

Gleich, A. von, Pade, Ch., Petschow, U. \& Pissarskoi. E. 2009. Potentials and Trends in Biomimetics, Springer Switzerland.

Bar-Cohen, Y. 2006. Biomimetics, Biologicaly Inspired Technologies. Boca Raton FL, CRC Press, Taylor \& Francis Group, LLC.

Benyus, J. M. 1997. Biomimicry, Innovation Inspired by Nature. Harper Perennial, New York. http://www.globalstewards.org/biomimicry-nine-laws-of-nature.htm.

Almeida, H. A. \& Oliveira, E. S. G. 2016. Sustainability Based on Biomimetic Design Models. In: Muthu S., Savalani M. (eds), Handbook of Sustainability in Additive Manufacturing. Environmental Footprints and Eco-design of Products and Processes, Springer, Singapore.

Rossin, K. J. 2010. Biomimicry: nature's design process versus the designer's process. WIT Transactions on Ecology and the Environment 138: 559-570.

Luca, D. De, 2016. The power of the Biomimicry Design Spiral.

Bahill, A. T. \& Botta, R. 2008. Fundamental Principles of Good System Design. In Engineering Management Journal 20(4): 9-17.

https://asknature.org/resource/biomimicry-taxonomy/. 
Mishra, R. \& Militky, J. \& Venkataraman, M. 2019. Nanoporous materials, Nanotechnology in Textiles, Theory and Application. The Textile Institute Book Series, 311-353. https://asknature.org/idea/dupont-nomex-and-kevlar-honeycomb-composite-materials/.

Barton, D.C. \& Fieldhouse, J.D. 2018. Vehicle Structures and Materials. In: Automotive Chassis Engineering, Cham: Springer, 215-254.

Heilbron, J. L. 2013. Platonic solid. Encyclopedia Britannica.

Larson, E. J. 2006. Evolúcia. Neobyčajná história jednej vedeckej teórie. Slovak edition, Bratislava: Slovart.

Pischinger, S. \& Seiffert, U. 2016. Vieweg Handbuch Kraftfahrzeugtechnik. Springer Fachmedien Wiesbaden, Wiesbaden.

Fiolet, S. 2020. The Secrets of the Platonic Solids and Sacred Geometry. Sacred creation.

Altach, J. \& Bader, B. \& Fröhlich, T. \& Klaiber, D. \& Vietor, T. 2019. Approach to the systematic categorization and qualitative evaluation of multi-material designs for use in vehicle body structures, Procedia CIRP, 84: 908-915. 